\title{
Risk factors influencing the bone health in perimenopausal and postmenopausal women
}

\author{
Reetu Hooda, Manisha Upadhyay*, Hemant More, Tek C. Yadav
}

Department of Obstetrics and Gynecology, Pandit Bhagwat Dayal Sharma, Post Graduate Institute of Medical Sciences, Rohtak, Haryana, India

Received: 27 January 2017

Accepted: 02 March 2017

*Correspondence:

Dr. Manisha Upadhyaya,

E-mail: docmanisha.u@gmail.com

Copyright: ( ) the author(s), publisher and licensee Medip Academy. This is an open-access article distributed under the terms of the Creative Commons Attribution Non-Commercial License, which permits unrestricted non-commercial use, distribution, and reproduction in any medium, provided the original work is properly cited.

\section{ABSTRACT}

Background: Bone loss is being increasingly identified in premenopausal and early postmenopausal women. The significance of low bone mineral density (BMD) in females needs to be addressed. Female reproductive system plays a major role in regulating the bone loss from menarche to senescence. The purpose of our study is to identify the menstrual and reproductive factors that may lead to decreased bone mass during the premenopausal period so that early intervention could lead to improved bone health.

Methods: The study was conducted on 100 women aged 40 - 60 years attending the outpatient department in Pandit Bhagwat Dayal Sharma PGIMS, Rohtak, Haryana, India. Their age, parity, body mass index, age at menarche, age at first pregnancy, duration of breast feeding, use of combined oral contraceptive, interpregnancy interval and BMD values were recorded. BMD was measured by dual- energy x-ray absorptiometry. Pearson test was used for correlation analysis. Comparison between the groups was conducted using analysis of variance (ANOVA) and Tukey's test.

Results: A significant negative correlation was established between parity, age at menarche, duration of breast feeding and BMD values. On the other hand, BMI and duration of oral contraceptive use showed a significant positive correlation with BMD values.

Conclusions: Identification of risk factors for low BMD will provide the opportunity for early intervention to preventosteoporosis and will reduce the burden of unnecessary BMD testing in elderly age group for screening of osteoporosis.

Keywords: Bone loss, Bone mineral density, Osteoporosis, Postmenopausal women

\section{INTRODUCTION}

Osteoporosis is a progressive skeletal disease manifested by decreased bone mineral density and collateral damage to the bone microarchitecture, which can subsequently lead to impaired skeletal strength and elevated susceptibility to fractures. ${ }^{1}$ It is a common and complex health problem in the elderly women. It has been statistically observed that over $50 \%$ of the adults at age 50 years or older suffer from osteoporosis, among which approximately $70 \%$ are postmenopausal females. ${ }^{2}$ BMD has been widely accepted as a surrogate parameter for the diagnosis of osteopenia and osteoporosis which supports its utility as a diagnostic avenue for abnormal bone mass. ${ }^{3}$ Many reproductive and menstrual factors like parity, breastfeeding, age at first pregnancy, age at menarche, use of combined oral contraceptives (COCs) and duration of menopause might influence the risk of osteoporosis. Our aim was to investigate the correlation of these factors with the BMD of postmenopausal women and in women undergoing menopause transition phase. Firstly, it will help in reducing the unnecessary BMD testing in elderly women and secondly, it will help in prevention of osteoporosis by helping the clinician to assess the need for early intervention. 


\section{METHODS}

This study was conducted on 100 women aged 40 - 60 years attending the outpatient department of Pandit Bhagwat Dayal Sharma PGIMS, Rohtak and advised BMD testing. All participants were given a structured questionnaire which was used to obtain their demographic, reproductive and menstrual history details. The sample consisted of patients who have attained menopause or are in the phase of menopause transition.

\section{Exclusion criteria}

- Women with early or secondary menopause.

- Women who have taken any drug known to affect bone metabolism.

- Women with any systemic and metabolic disease.

Age, parity, body mass index (BMI), age at menarche, age at first pregnancy, duration of breast feeding, use of combined oral contraceptive, interpregnancy interval and BMD values were recorded.BMI was calculated as weight $(\mathrm{kg}) /$ height $\left(\mathrm{m}^{2}\right)$. According to National Institute of Health and WHO, individuals are classified as: underweight $\left(\mathrm{BMI}<18.5 \mathrm{~kg} / \mathrm{m}^{2}\right.$ ), normal weight (BMI $\geq 18.5-24.9 \mathrm{~kg} / \mathrm{m}^{2}$ ) and overweight (BMI $\geq 25$ $\left.29.9 \mathrm{~kg} / \mathrm{m}^{2}\right) .{ }^{4,5}$ Duration of breast feeding and oral contraception was recorded in months. Measurement of bone mass was performed by dual- energy x-ray absorptiometry (DEXA) at the femoral neck by calculating the T-score. T-score is the standard deviation (SD) difference between a patient's BMD and that of a young adult reference population. According to WHO, Tscore $\geq-1 \mathrm{SD}$ indicates normal bone density, while $\mathrm{T}$ scores between $-1 \mathrm{SD}$ to $-2.5 \mathrm{SD}$ and $\geq-2.5 \mathrm{SD}$ is defined as osteopenia and osteoporosis, respectively. ${ }^{6}$

Statistical analysis was performed using SPSS version 22. The demographic findings were reported in terms of mean and the standard deviation values. Comparison between the groups was conducted using analysis of variance (ANOVA) and Tukey's test. Pearson Correlation analysis was used in the evaluation of correlations. $\mathrm{P}$ value of less than 0.05 was considered statistically significant.

\section{RESULTS}

The sample consists of 100 women of perimenopausal and postmenopausal group and their age varied between 40- 60 years. Table 1 shows the mean values for age, BMI, parity, age at menarche, age at first pregnancy, duration of breast feeding, duration of oral contraceptive use and BMD values of the participants.

Table 1: Demographic, reproductive and menstrual characteristics of subjects.

\begin{tabular}{|lllll|}
\hline & $\mathrm{n}$ & Minimum & Maximum & Mean \pm SD \\
\hline Age (years) & 100 & 40 & 60 & $50.15 \pm 5.97$ \\
\hline BMI $\left(\mathrm{Kg} / \mathrm{m}^{2}\right)$ & 100 & 11.70 & 39.40 & $25.65 \pm 4.28$ \\
\hline Parity & 100 & 01 & 07 & $3.53 \pm 1.23$ \\
\hline Age at menarche (years) & 100 & 11 & 16 & $14.03 \pm 1.10$ \\
\hline Age at first pregnancy (years) & 100 & 16 & 30 & $18.41 \pm 1.76$ \\
\hline Duration of breast feeding (months) & 100 & 08 & 52 & $22.15 \pm 9.12$ \\
\hline Total duration of OCP use (months) & 100 & 0 & 24 & $2.65 \pm 5.70$ \\
\hline BMD (T-score) & 100 & -4.4 & 2.5 & $-1.19 \pm 1.34$ \\
\hline
\end{tabular}

Table2: Relationship between the demographic, reproductive and menstrual characteristics and BMD values of the subjects.

\begin{tabular}{|lll|}
\hline Age & $\begin{array}{l}\text { Correlation with the BMID values of } \\
\text { the subjects }(r)\end{array}$ & \begin{tabular}{l} 
Sig.(2-tailed) \\
\hline BMI
\end{tabular} \\
\hline Parity & -0.063 & 0.536 \\
\hline Age at menarche & $0.427^{*}$ & 0.000 \\
\hline Age at first pregnancy & $-0.346^{*}$ & 0.000 \\
\hline Interpregnancy interval & $-0.611^{*}$ & 0.000 \\
\hline Duration of breastfeeding & 0.116 & 0.249 \\
\hline Duration of OCP use & 0.089 & 0.378 \\
\hline Duration of menopause & $-0.794^{*}$ & 0.000 \\
\hline
\end{tabular}

* Correlation is significant at the $\mathrm{p}$ value $<0.05$ level 
The demographic, reproductive and menstrual risk factors which were considered to be significant in our study were correlated to $\mathrm{t}$-scores of the participants and their correlation is demonstrated in Table 2. A significant negative correlation was established between parity, age at menarche, duration of breast feeding and BMD values. On the other hand, BMI and duration of combined oral contraceptives use showed a significant positive correlation with BMD values.

Table 3: BMD values among the underweight, normal weight and overweight women.

\begin{tabular}{|llll|}
\hline $\mathrm{N}$ & Underweight $(\mathrm{BMI}<\mathbf{1 8})$ & Normal weight $(\mathrm{BMI}$ 18-24.9) & Overweight( BMI $\geq 25)$ \\
\hline $\begin{array}{l}\mathrm{BMD} \\
(\mathrm{mean} \pm \mathrm{SD})\end{array}$ & 5 & 33 & 62 \\
\hline p-value & $-1.600 \pm 0.5612$ & $-1.639 \pm 1.3043$ & $-.932 \pm 1.3531$ \\
\hline
\end{tabular}

*p value $<0.05$ is considered significant

Table 4: Age at first pregnancy and its effect on BMD values.

\begin{tabular}{|llll|}
\hline & $<20$ years $($ group 1$)$ & $20-25$ years $($ group 2$)$ & $>25$ years $($ groujp3) \\
\hline $\mathrm{n}$ & 48 & 47 & 5 \\
\hline Mean \pm SD (BMD) & $-1.519 \pm 1.2679$ & $-.862 \pm 1.3480$ & $-1.300 \pm 1.5443$ \\
\hline P value & Group 1 $-2(0.044)^{*}$ & Group 2 - 3 $(0.760)$ & Group 3 - 1 $(0.934)$ \\
\hline
\end{tabular}

*p value $<0.05$ is considered significant

Table 5: Effect of duration of combined oral contraceptives use on BMD values.

\begin{tabular}{|lllll|}
\hline & Nil (group1) & $<6$ months (group2) & 6 -12 months (group3) & $>12$ months (group 4) \\
\hline $\mathrm{n}$ & 74 & 8 & 11 & 7 \\
\hline Mean \pm SD (BMD) & $-1.52 \pm 1.20$ & $-0.875 \pm 1.29$ & $-0.173 \pm 1.43$ & $0.271 \pm 0.89$ \\
\hline \multirow{2}{*}{ P value } & Group 1-2 $(0.484)$ & Group 2 - 3 $(0.606)$ & & \\
& Group 1-3 $(0.005) *$ & Group 3-4 (0.876) & \\
& Group 1-4 $(0.002) *$ & Group 2 - 4 (0.274) & & \\
\hline
\end{tabular}

The subjects were categorized in to three groups according to BMI as shown in Table 3, underweight $\left(\mathrm{BMI}<18.5 \mathrm{~kg} / \mathrm{m}^{2}\right)$, normal weight $(\mathrm{BMI} \geq 18.5$ $\left.24.9 \mathrm{~kg} / \mathrm{m}^{2}\right)$ and overweight $\left(\mathrm{BMI} \geq 25-29.9 \mathrm{~kg} / \mathrm{m}^{2}\right)$ and when the mean BMD values of these groups were compared it showed that the overweight women have significantly high BMD than normal weight women ( $p$ value $<0.05)$.

On comparing the mean BMD values of subjects on the basis of different age at the time of first pregnancy (Table 4) it was seen that the women who became pregnant before the age of 20 years have significantly low BMD values than women who had their first child after the age of 20 years ( $p$ value $<0.05$ ).

Women were again categorized into four groups depending on their duration of combined oral contraceptive use as shown in Table 5 and their BMD values were compared. The BMD values of women who never used COCs was significantly lower than those who used them for more than 6 months but there was no significant difference between the BMD values of women who never used COCs and those who used them for less than 6 month. The difference of BMD values was also not significant between women who used COCs for 6-12 months and those who used them for more than 12 months.

\section{DISCUSSION}

As etiology of osteoporosis is multifactorial, several studies have been conducted analyzing the relationship of different demographic, menstrual and reproductive factors with bone mineral density of elderly women but all of them have controversial results. No definite sole cause can be put forward to be responsible for osteoporosis due to the interaction between the different risk factors. In our study we found that early menarche, longer reproductive period, increased BMI, use of COCs, low parity and shorter period of lactation were associated with high BMD in peri-menopausal and postmenopausal females.

Several studies have established a significant negative correlation between age and BMD. ${ }^{7,8,9}$ While on the contrary in our study age doesn't seem to significantly 
affect the BMD which might be due to narrow range of age of the participants (40-60 years) included in our study.

Among multiple factors affecting the bone mineral density, body weight and body mass index exert a prominent impact on the BMD..$^{10}$ Increased body weight has been demonstrated to correlate with endocrine alterations, which can positively influence bone metabolism in a direct or indirect manner. ${ }^{11}$ Notably, low body weight or BMI likely predispose postmenopausal females to rapid bone loss and low bone mass, which are considered to play crucial roles in the pathogenesis of postmenopausal female's osteoporosis. ${ }^{3}$ This fact has been demonstrated in our study also. We found a significant positive correlation of body mass index with BMD. The overweight subjects of our study showed significantly higher BMD than normal weight subjects. The underlying mechanism involves multiple factors. Osteocytes are thought to sense mechanical loading of the skeleton. It is possible that in response to greater mechanical loading, osteocytes send signals to other bone cells that either reduce osteoclastic bone resorption, as evidenced by an inverse association between bone turnover and BMI or increase osteoblastic bone formation resulting in an attenuation of bone loss in heavier women. ${ }^{12}$ Increased production of estrogens by adipose tissue may also contribute to the association between BMD and body weight. It has been shown that individuals with higher BMI are more likely to suffer hyperinsulinemia, as impaired production of insulin-like growth factor-1 (IGF-1)-binding globulins results in increased expression of IGF-1, which stimulates the differentiation of osteoblasts and promotes bone formation. ${ }^{13}$ It should be noted that body weight and BMI also reflect the nutritional status of humans, and malnutrition directly affects bone reconstruction. ${ }^{14}$ Johnson et al, Kim et al and Wu SF and Du XJ also demonstrated positive correlation of body mass index and BMD in their study. ${ }^{9,15,16}$

Pregnancy and lactation are proposed as two risk factors for osteoporosis. There are some hypotheses which support the contributory effect of pregnancy and lactation on osteoporosis later in life. High calcium demand during pregnancy and lactation and low estrogenic state support those hypotheses. Numerous studies have investigated on the issue but there is no consensus about the contributory effect of pregnancy and lactation on osteoporosis. There is strong evidence that calcium is mobilized from the maternal skeleton to that of the developing fetus during pregnancy. However, the eventual return of BMD to pre pregnancy values suggests that maternal bone loss may not be permanent. Pregnancy and prolong lactation can have either beneficial or detrimental effect on bone as demonstrated by various researchers. Some studies suggest the protective effect of parity and duration of lactation on BMD while some mentioned a negative association and some found no association.
Salari and Abdollahi in their systematic review concluded that despite of controversial results of various researches, pregnancy may have protective effect on bone especially if followed by lactation as there is possibility of complete restoration of BMD after weaning. ${ }^{17}$ To \& Wong et al also observed less BMD decrement in multiparous women compared to primiparous. ${ }^{18}$ In a recent study, Wiklund et al displayed the protective effect of lactation on bone size and strength in direct correlation with its duration while Yazici et al found no effect of lactation and its duration on postmenopausal women. ${ }^{19,20}$ Kauppi et al also confirmed the positive effect of parity on BMD and showed inverse association between risk of hip fracture and parity. ${ }^{21}$ Moller et al concluded in their study that pregnancy and breastfeeding cause a reversible bone loss. ${ }^{22}$ Lebel et al supported the fact that pregnancy and breastfeeding has no detrimental effect on BMD. ${ }^{23}$

In contrast to all above studies we found a significant negative correlation between multiparity, duration of breastfeeding and BMD suggesting their detrimental effect on bone health. There are several studies in the literature which support the results of our study.,24,25,26 Lower educational level and limited knowledge of birth control methods are the major factors leading to multiparity in developing country like ours . Moreover, prolonged lactation period, poor nutrition and lack of calcium supplementation during pregnancy and lactation lead to decreased BMD in multiparous females.

Several previous studies have shown a significant negative correlation of age at menarche and BMD. ${ }^{27,28,29}$ Same results have been demonstrated in the current study. Of the variance in BMD, 60-80\% is explained by genetics which could explain the close relationships between BMD and pubertal timing. ${ }^{30,31}$ Menarche may be having a stimulating effect on the development of bone by increasing the osteoblastic activity via accompanying the unsettled estrogen. ${ }^{32}$ But there are studies which don't support the above result. Johnson et al concluded in their study that age at menarche is not a significant predictor of BMD. ${ }^{9}$ Waugh et al also found inconsistent and insufficient evidence for the effect of age at menarche on BMD. $^{33}$

Evidence shows that pregnancy at an earlier age may result in lower bone density and increased risk for perimenopausal and postmenopausal bone loss as both the mother's and the fetus's skeletons are concurrently maturing. ${ }^{34}$ The studies support this evidence too including the current study. ${ }^{35}$

Teegarden et al stated in their study that $80 \%$ of all women have used oral contraceptives pills (OCP), but OCP use may prevent attainment of maximal peak bone mass in young women and thus increase the risk of osteoporosis later in life. ${ }^{36}$ Johnson et al also concluded that use of oral contraceptives is not a significant predictor of BMD. ${ }^{9}$ On the contrary Sultana et al found in their study that OCP users had higher mean BMD 
compared to non-users who had lower mean BMD. This indicates that OCP non-users had elevated bone turn over, which appears to adversely influence BMD and fracture risk. ${ }^{37}$ Our study is also in agreement with the above study. Hence, it can be concluded that one of the important non-contraceptive benefit of OCP may be positive effects on bone.

Most of the studies suggest duration of menopause as the significant risk factor for low BMD. ${ }^{8,15}$ This is due to sudden drop of ovarian estrogen around menopause. Accelerated bone loss begins about 2 to 3 years before the last menses and continues until 3 to 4 years after menopause. There is $2 \%$ bone loss annually around menopause, slowing to $1 \%$ to $1.5 \%$ annually thereafter. ${ }^{38,39}$ Finkelstein et al also suggested that BMD loss increases substantially in the late perimenopause and remains rapid in the first few postmenopausal years. ${ }^{40}$ However we didn't find any statistically significant correlation between BMD and duration of menopause. This might be due to the inclusion of early menopausal females (up to 60 years) in our study and not the late menopausal.

We found in our study that multiparity, low BMI, short reproductive period, lack of use of oral contraceptives and prolonged breastfeeding are the determining risk factors for low BMD in peri and postmenopausal women. Women with above risk factors should undergo screening for osteoporosis and assessment of risk factors prior to screening for osteoporosis will definitely reduce the burden of unnecessary testing. Moreover, if young women are made aware of these risk factors it could help in reducing the risk of osteoporosis later in life.

\section{ACKNOWLEDGEMENT}

Author would like to thank the technician conducting the DEXA scan for BMD testing in Pandit Bhagwat Dayal Sharma, PGIMS, Rohtak, Haryana, India for support.

Funding: No funding sources

Conflict of interest: None declared

Ethical approval: Not required

\section{REFERENCES}

1. Song JF, Jing $\mathrm{ZZ}, \mathrm{Hu} \mathrm{W}, \mathrm{Su} \mathrm{YX}$. Association between single nucleotide polymorphisms of the osteoprotegerin gene and postmenopausal osteoporosis in Chinese women. Genet Mol Res. 2013;12(3):3279-85.

2. Lee YH, Song GG. Efficacy and safety of monthly $150 \mathrm{mg}$ oral ibandronate in women with postmenopausal osteoporosis: a systematic review and meta-analysis of randomized controlled trials. Korean J Intern Med. 2011;26(3):340-7.

3. Fu X, Ma X, Lu H, He W, Wang Z, Zhu S. Associations of fat mass and fat distribution with bone mineral density in pre- and postmenopausal Chinese women. Osteoporos Int. 2011;22(1):113-9.

4. Clinical Guidelines on the identification, evaluation, and treatment of overweight and obesity in adults-the evidence report. National Institutes of Health. Obes Res. 1998;6(2):51-209.

5. Obesity: preventing and managing the global epidemic. Report of a WHO consultation. World Health Organ Tech Rep Ser. 2000;894:1-253.

6. Assessment of fracture risk and its application to screening for postmenopausal osteoporosis. Geneva, 1994.Available at http:// whqlibdoc. who.int /trs /WHO_TRS_843.pdf. Accessed on 9 March 2012.

7. Ghare M, Ozgoli G, Aghdashi MA, Salmani F. Prevalence and risk factors of osteoporosis in women referring to the bone densitometry academic center in Urmia, Iran. Glob J Health Sci. 2015;8(7):135-45.

8. Lo SS. Bone health status of postmenopausal Chinese women. Hong Kong Med J. 2015;21(6):53641.

9. Johnson AK, Ford MA, Jones TL, Nahar VK, Hallam JS. Predictors of bone mineral density in african-american and caucasian college-aged women. Health Promot Perspect. 2015;5(1):14-23.

10. Mendez JP, Mejia D, Pedraza J, Vázquez RM, Soriano R, García E, et al. Bone mineral density in postmenopausal Mexican-Mestizo women with normal body mass index, overweight, or obesity. Menopause. 2013;20(5):568-72.

11. Zhao LJ, Jiang H, Papasian CJ, Maulik D, Drees B, Hamilton $\mathbf{J}$ et al. Correlation of obesity and osteoporosis: effect of fat mass on the determination of osteoporosis. J Bone Miner Res. 2008;23(1):1729.

12. Ravn P, Cizza G, Bjarnason NH, Thompson D, Daley M, Wasnich RD et al. Low body mass index is an important risk factor for low bone mass and increased bone loss in early postmenopausal women. early postmenopausal intervention cohort (EPIC) study group. J Bone Miner Res. 1999;14(9)1622-7.

13. Bredella MA, Torriani M, Ghomi RH, Thomas BJ, Brick DJ, Gerweck AV, et al. Vertebral bone marrow fat is positively associated with visceral fat and inversely associated with IGF-1 in obese women. Obesity. 2011;19(1):49-53.

14. Barreiro de LA, Vázquez KF, Méndez C, Mendoza D, Padrón LÁ, García ME. The relationship of nutritional status, body and mandibular bone mineral density, tooth loss and fracture risk (FRAX) in preand postmenopausal women with periodontitis. Nutr Hosp. 2014;29(6):1419-26.

15. Kim S, Jung J, Jung JH, Kim SK, Kim RB, Hahm JR. Risk Factors of bone mass loss at the lumbar spine: a longitudinal study in healthy korean pre- and perimenopausal women older than 40 years. PLoS One. 2015;10(8):e0136283.

16. Wu SF, Du XJ. Body Mass index may positively correlate with bone mineral density of lumbar vertebra and femoral neck in postmenopausal females. Med Sci Monit. 2016;22:145-51. 
17. Salari P, Abdollahi M. The influence of pregnancy and lactation on maternal bone health: a systematic review. J Family Reprod Health. 2014;8(4):135-48.

18. To WW, Wong MW. Changes in bone mineral density of the os calcis as measured by quantitative ultrasound during pregnancy and 24 months after delivery. Aust NZJ Obstet Gynaecol. 2011;51(2):166-71.

19. Wiklund $\mathrm{PK}, \mathrm{Xu} \mathrm{L}$, Wang $\mathrm{Q}$, Mikkola $\mathrm{T}$, Lyytikäinen A, Vőlgyi E, et al. Lactation is associated with greater maternal bone size and bone strength later in life. Osteoporos Int. 2012;23(7):1939-45.

20. Yazici S, Korkmaz U, Erkan M, Korkmaz N, Erdem A, Alçelik A, et al. The effect of breast-feeding duration on bone mineral density in postmenopausal Turkish women: a population-based study. Arch Med Sci. 2011;7(3):486-92.

21. Kauppi M, Heliővaara M, Impivaara O, Knekt $P$, Jula A. Parity and risk of hip fracture in postmenopausal women. Osteoporos Int. 2011;22(6):1765-71.

22. Møller UK, ViðStreym S, Mosekilde L, Rejnmark L. Changes in bone mineral density and body composition during pregnancy and postpartum. A controlled cohort study. Osteoporos Int. 2012;23(4):1213-23.

23. Lebel E, Mishukov Y, Babchenko L, Samueloff A, Zimran A, Elstein D. Bone mineral density in gravida: effect of pregnancies and breast-feeding in women of differing ages and parity. J Osteoporos. 2014;2014:897182.

24. Demir B, Haberal A, Geyik P, Baskan B, Ozturkoglu $\mathrm{E}$, Karacay $\mathrm{O}$, et al. Identification of the risk factors for osteoporosis among postmenopausal women. Maturitas. 2008;60(3):253-6.

25. Khoo CC, Woo J, Leung PC, Kwok A, Kwok T. Determinants of bone mineral density in older postmenopausal Chinese women. Climacteric. 2011;14(3):378-83.

26. Mejía D, Madrid G, Medina G, Espinosa L, Chiu MC, Cetina T et al. Risk factors and impact on bone mineral density in postmenopausal Mexican mestizo women. Menopause. 2011;18(3):302-6.

27. Kang H, Chen YM, Han G, Huang H, Chen WQ, Wang X, et al. Associations of age, bmi, and years of menstruation with proximal femur strength in chinese postmenopausal women: a cross-sectional study. Int $\mathrm{J}$ Environ Res Public Health. 2016;13(2):157.

28. Kuh D, Muthuri SG, Moore A, Cole TJ, Adams JE, Cooper $\mathrm{C}$, et al. Pubertal timing and bone phenotype in early old age: findings from a British birth cohort study. Int J Epidemiol. 2016;45(4):1113-24.
29. Chevalley T, Bonjour JP, Ferrari S, Rizzoli R. Pubertal timing and body mass index gain from birth to maturity in relation with femoral neck BMD and distal tibia microstructure in healthy female subjects. Osteoporos Int. 2011;22(10):2689-98.

30. Bonjour JP, Chevalley T. Pubertal timing, bone acquisition, and risk of fracture throughout life. Endocr Rev. 2014;35(5):820-47.

31. Day FR, Sullivan B, Hinds DA, Finucane HK, Murabito JM, Tung JY, et al. Shared genetic aetiology of puberty timing between sexes and with health related outcomes. Nat Commun. 2015;6:8842.

32. Ito M, Yamada M, Hayashi K, Ohki, Uetani M, Nakamura T. Relation of early menarche to high bone mineral density. Calcif Tissue Int. 1995;57(1):11-4.

33. Waugh EJ, Lam MA, Hawker GA, McGowan J, Papaioannou A, Cheung AM et al. Risk factors for low bone mass in healthy 40-60 year old women: a systematic review of the literature. Osteoporos Int. 2009;20(1):1-21.

34. Sowers MF. Premenopausal reproductive and hormonal characteristics and the risk for osteoporosis. In: R. Marcus, D. Feldman and J. Kelsey. Osteoporosis, 2th edition. Academic Press, San Diego. 721-39.

35. Ozdemir F, Demirbag D, Rodoplu M. Reproductive factors affecting the bone mineral density in postmenopausal women. Tohoku J Exp Med. 2005;205(3):277-85.

36. Teegarden D, Legowski P, Gunther CW, McCabe GP, Peacock M, Lyle RM. Dietary calcium intake protects women consuming oral contraceptives from spine and hip bone loss. J Clin Endocrinol Metab. 2005;90(9):5127-33.

37. Sultana S, Choudhury S, Choudhury SA. Serum alkaline phosphatase and bone mineral density: to assess bone loss in oral contraceptive pill user. Mymensingh Med J. 2002;11(2):107-9.

38. Recker R, Lappe J, Davies K, Heaney R. Characterization of perimenopausal bone loss: a prospective study. J Bone Miner Res. 2000;15(10):1965-73.

39. Pouillès JM, Trémollières F, Ribot $\mathrm{C}$. Vertebral bone loss in perimenopause. Results of a 7-year longitudinal study. Presse Med. 1996;25(7):277-80.

40. Finkelstein JS, Brockwell SE, Mehta V, Greendale GA, Sowers MR, Ettinger B, et al. Bone mineral density changes during the menopause transition in a multiethnic cohort of women. J Clin Endocrinol Metab. 2008;93(3):861-8.

Cite this article as: Hooda R, Upadhyay M, More $\mathrm{H}$, Yadav TC.Risk factors influencing the bone health in perimenopausal and postmenopausal women .Int J Reprod Contracept Obstet Gynecol 2017;6:1467-72. 